\title{
Study on Incidence of Helicobacter Pylori in Patients of Gastroduodenal Perforation Admitted in Tertiary Care Center - Hamidia Hospital Bhopal
}

\author{
Mahim Koshariya ${ }^{1}$, Avinash Pratap Singh ${ }^{1}$, Samir Shukla ${ }^{1}$, R.K. Jain ${ }^{2}$, M.C. Songra ${ }^{1}$
}

Corresponding author:

Mahim Koshariya, MS, FIASGO, FMAS

Department of Surgery,

Gandhi Medical College \& Associated

Hamidia Hospital, Bhopal, India

E-mail: mahimk2000@yahoo.co.uk
'Department of Surgery, Gandhi Medical College and Associated Hamidia Hospital Bhopal India ${ }^{2}$ Department of Medicine, Gandhi Medical College and Associated Hamidia Hospital Bhopal India

\section{ABSTRACT}

Introduction: Acid-reduction surgery has been strongly advocated in past for perforated peptic ulcers because of the high incidence of ulcer relapse after simple closure. Since Most patients with Gastroduodenal perforation are associated with Helicobacter pylori (H. pylori) infection, Simple oversewing procedures either by an open or laparoscopic approach together with $\mathrm{H}$. pylori eradication appear to supersede definitive ulcer surgery.

Material and Methods: Total number of 70 patients were included in this prospective study with diagnosis of perforation peritonitis admitted in emergency ward. These patients were operated in emergency by simple closure of perforation with omental patch repair. Peroperative biopsy sample was taken from margin of perforation and sent for staining by $\mathrm{H} \& \mathrm{E}$ and Giemsa staining for $\mathrm{H}$. pylori. After 15 days endoscopic biopsy was taken from gastric antrum for H. pylori staining. Anti H. Pylori Eradication Therapy (Triple therapy--1 PPI +2 antibiotic) for 14 days was given to the positive cases. These patients were followed for 1 year for recurrence of ulcer.

Results: Out of 70 consecutive patients (mean age $=47$ years, range 15-75) of perforation H. pylori was seen in 48 patients (68.57\%). Total 28 patients (40\%) were having h/o use of NSAIDS in recent past. Male to female ratio was about 3:1 and most common age group was 46-55 years. In the $\mathrm{H}$. pylori positive patients, Anti $\mathrm{H}$ pylori eradication therapy was given. These all patients are in follow up and are asymptomatic in 3 months.

Conclusions: H. pylori is strongly associated with Gastro duodenal perforation, (48/70) $68.57 \%$ were positive for $\mathrm{H}$. pylori. Gastric perforation was more common than duodenal perforation and prepyloric region was commonest site. For $\mathrm{H}$. pylori detection, biopsy and staining is a good method. Early Anti H. pylori therapy for patients of Gastro duodenal perforation who were positive for $\mathrm{H}$. pylori, provide an excellent cure after simple closure of perforation.

Key words: H. pylori, gastroduodenal perforation, peptic ulcers

\section{INTRODUCTION}

Perforated gastric and duodenal ulcer remains a dramatic surgical 
emergency and is a formidable complication of ulcer disease associated with significant morbidity and mortality. It requires immediate surgical intervention because of fatal outcome due to sepsis. Gastric perforation is common sequel of peptic ulcer disease. The annual incidence of ulcer is $1.8 \%$ or roughly 500000 thousand new cases per year. About 9000 patients die from complications of their Peptic Ulcer Disease (1).

Roughly $75 \%$ gastric ulcer and $90 \%$ of duodenal ulcer are associated with the $H$. pylori infection (2). The $2^{\text {nd }}$ most common cause of PUD is NSAID ingestion. NSAIDS induced ulcer are more common in stomach than duodenum (3). Smoking, alcohol, stress and steroid are other important risk factors for peptic perforation. It is widely believed that it is silent chronic ulcer that perforates specially in patients who are being treated with steroid or NSAIDS for one or another reason, usually symptoms of perforation occur with dramatic suddenness.

Exact determination between $\mathrm{H}$. pylori and peptic perforation is not available, mostly because exact data are not available from developing countries but this organism must make the major contributor to the etiology of the disease and in the maintenance of chronicity of the ulcer (4). If this infection is cured, ulcers and their complications rarely occur (5).

Current scientific evidence points to a strong association between $\mathrm{H}$. pylori and gastro duodenal perforation (6). Cure of the infection results in a marked reduction in ulcer recurrence. Permanent cure of the peptic ulcer can be achieved (7).

The gold standard for diagnosis of $\mathrm{H}$. pylori infection has been biopsy-obtained during endoscopy-followed by testing of urease and/or histologic staining with heamatoxylin and eosin (8). However, no single test has yet emerged as definitive in daily clinical practice for several reasons.

Gastric antrum is commonly involved in chronic active gastritis caused by H. pylori (9) Endoscopic gastric biopsies stained by variety of histological stains is gold standard in the diagnosis of H. pylori (10). The pyloric antrum has been the site of biopsy in many studies with single distal antral biopsy having a sensitivity of $97 \%$ for H. pylori detection (11).

As gastro duodenal perforation is a common problem in our emergency surgical ward and there are not much studies on the association between Helicobacter pylori and gastro duodenal perforation. So with these things keeping in mind present study was carried out to see the incidence of $\mathrm{H}$. pylori in peptic perforation.

\section{AIMS AND OBJECTIVES}

1. To determine the incidence of $\mathrm{H}$. pylori in gastro duodenal perforation patients admitted in Hamidia Hospital Bhopal.

2. To give anti $\mathrm{H}$ pylori regime for $\mathrm{H}$. pylori positive patients to prevent the recurrence of ulcer.

3. To study various risk factors associated with gastro-duodenal perforation.

\section{MATERIALS AND METHODS}

The present study was carried out in Gandhi Medical College and Associated Hamidia Hospital Bhopal from October 2011 to October 2012. Study entitled "Incidence of Helicobacter Pylori in Gastroduodenal Perforation Patients Admitted in Hamidia Hospital Bhopal". Total 70 patients were included in this study with diagnosis of perforation peritonitis admitted in emergency ward. It was a prospective study.

\section{Case selection}

\section{Inclusion criteria}

All patients of gastroduodenal perforation admitted in Hamidia Hospital Bhopal.

\section{Exclusion criteria}

Patients age $<12$ years are not included in this study. Patients of perforation peritonitis due to blunt injury or penetrating injury were not included

\section{Methodology}

A total number of 70 patients were included in this study, all were admitted in emergency wards with a clinical diagnosis of perforation peritonitis. Patient's history was taken. Relevant clinical, biochemical and radiological examinations were done to establish the diagnosis of peptic ulcer perforation. All of the patients were operated. Intraoperatively the site and size of the ulcer (fig. 1), condition of surrounding duodenum and omentum, and also any other additional finding was noted. In all patients surgical procedure performed in emergency was simple closure of perforation with omental patch repair. Per operative biopsy sample was taken from the margin of perforation and sent for staining by Hematoxylin-eosin and Giemsa staining for H. pylori. (fig. 2) Postoperatively patient were managed by nil by mouth, ryle's tube insertion till bowel sounds were heard and flatus appreciated by the patient. Drains were taken out according to the amount of drainage, Ryles tube was removed after 3-5 days. After 


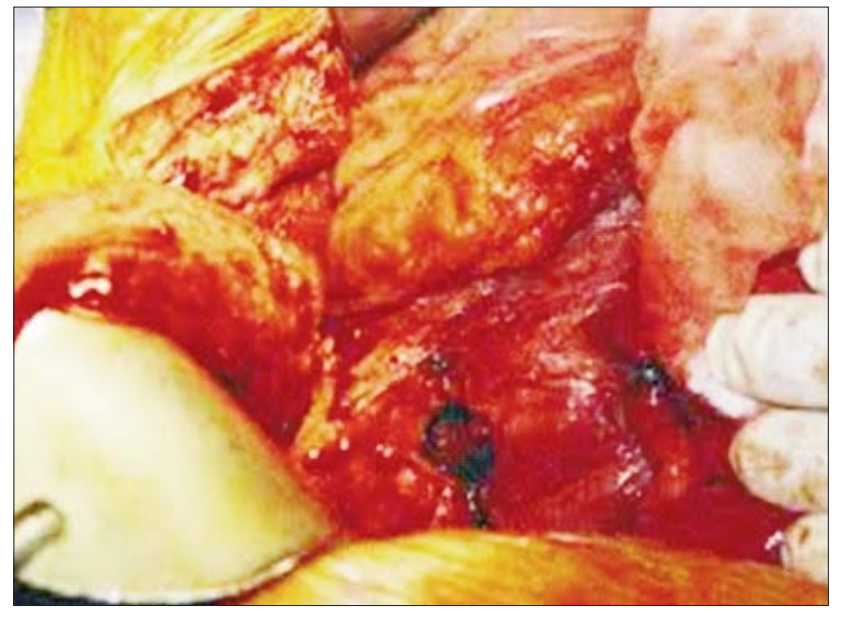

Figure 1 - Intraoperative picture of gastric perforation

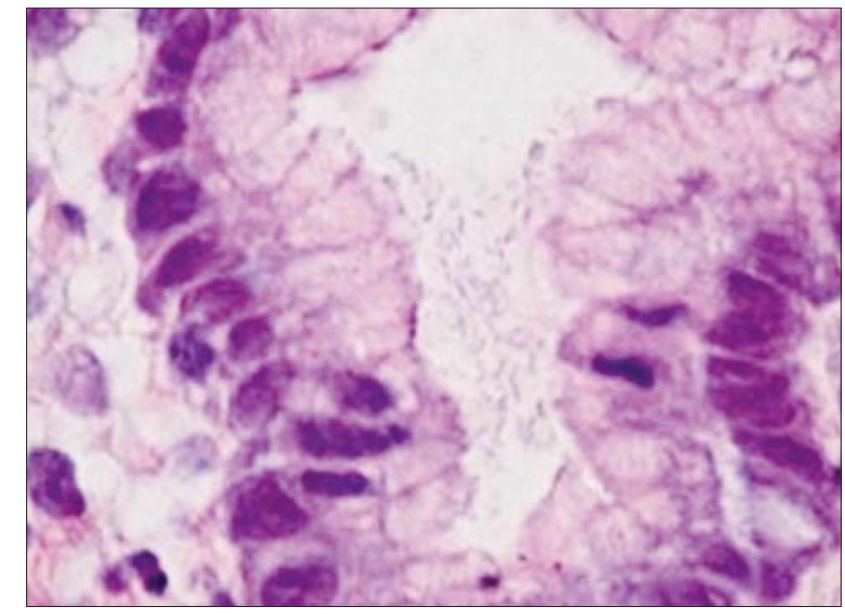

Figure 2 - Appearance of $\mathrm{H}$. pylori with H \& E staining in microscope

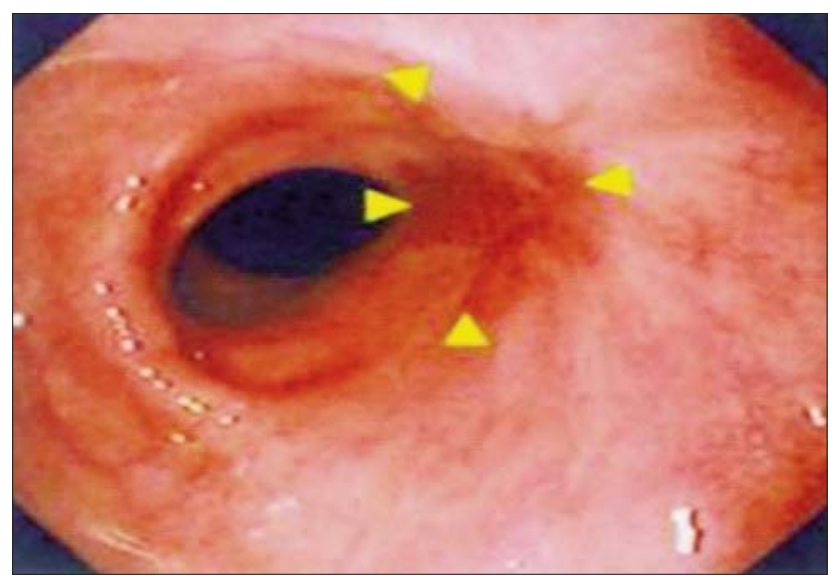

Figure 3 - Endoscopic view of repaired gastric perforation

15 days, six biopsy samples were taken endoscopically from gastric antrum for $\mathrm{H}$. pylori staining. (fig. 3) By cumulative data incidence of $\mathrm{H}$. pylori was determined. H. pylori Eradication Therapy (triple therapy 1PPI +2 antibiotics) was given for 14 days to the positive cases. These patients will be followed for 1 year for recurrence of ulcer or perforation.

\section{OBSERVATIONS AND RESULTS \\ (TABLES 1-10, CHARTS1-14)}

\section{DISCUSSION}

Helicobacter pylori ever since its isolation from

Table 1 - Patients with different size of perforation

\begin{tabular}{lcc}
\hline Size of perforation & Total & $\%$ \\
\hline$<1 \mathrm{~cm}$ & 24 & 34.28 \\
\hline $1-2 \mathrm{~cm}$ & 42 & 60 \\
\hline$>2 \mathrm{~m}$ & 4 & 5.72 \\
\hline
\end{tabular}

Table 3 - Posivity of Helicobacter pylori in peroperative and postoperative biopsy

\begin{tabular}{lcc}
\hline Biopsy & Positive (IN 70) & $\%$ \\
\hline Per-operative (marginal biopsy) & $25 / 70$ & 35.7 \\
\hline $\begin{array}{l}\text { Post-operative } \\
\text { (endoscopic antral biopsy) }\end{array}$ & $48 / 70$ & 68.57 \\
\hline
\end{tabular}

Table 2 - Patient with the different site of perforation

\begin{tabular}{lcc}
\hline Site & Total & $\%$ \\
\hline Prepyloric & 38 & 54.28 \\
\hline Pyloric & 18 & 25.71 \\
\hline Duodenal & 14 & 20 \\
\hline
\end{tabular}

Table 4 - Number of patients with observed risk factors

\begin{tabular}{l|cc}
\hline Risk factors & =n & \%age \\
\hline Helicobacter pylori & $48 / 70$ & $68.57 \%$ \\
\hline Smoking & $22 / 70$ & $31.42 \%$ \\
\hline Stressful life style & $9 / 70$ & $12.85 \%$ \\
\hline Family history of proved DU & $8 / 70$ & $11.42 \%$ \\
\hline NSAIDs abuse & $28 / 70$ & $40 \%$ \\
\hline Steroid abuse & $6 / 70$ & $8.57 \%$ \\
\hline Alcohol intake & $19 / 70$ & $27.14 \%$ \\
\hline
\end{tabular}


Table 5 - Comparison of patients with perforated gastroduodenal ulcer found to be positive or negative for Helicobacter pylori

\begin{tabular}{lccc}
\hline & $\begin{array}{c}\text { Helicobacter } \\
\text { pylori positive } \\
\mathbf{4 8 ( 6 8 . 5 7 \% )}\end{array}$ & $\begin{array}{c}\text { Helicobacter } \\
\text { pylori negative } \\
\mathbf{2 2}(\mathbf{3 1 . 4 2 \% )}\end{array}$ & $\begin{array}{c}\text { Total } \\
\mathbf{7 0}(\mathbf{1 0 0 \% )}\end{array}$ \\
\hline Gastric ulcer & $40(71.42 \%)$ & $16(28.57 \%)$ & $56(80 \%)$ \\
\hline Duodenal ulcer & $8(57.14 \%)$ & $6(42.85 \%)$ & $14(20 \%)$ \\
\hline Sex: M/F & $38 / 10$ & $16 / 6$ & $54 / 16$ \\
& $(79 \% / 21 \%)$ & $(72 \% / 28 \%)$ & $(77 \% / 23 \%)$ \\
\hline Mean age (yr) & 45.5 & 45.7 & 45.56 \\
\hline Range (yr) & $15-68$ & $18-70$ & $45-70$ \\
\hline Past history of peptic ulcers & $6(12.5 \%)$ & $2(9.1 \%)$ & $8(11.4 \%)$ \\
\hline Current NSAlDs & $12(25 \%)$ & $16(72 \%)$ & $28(40 \%)$ \\
\hline
\end{tabular}

Table 7 - Patients with medical illness

\begin{tabular}{lcc}
\hline DISEASE & PRESENT & $\%$ \\
\hline Ischaemic Heart Disease & $4 / 70$ & 5.71 \\
\hline Diabetes Mellitus (DM) & $2 / 70$ & 2.85 \\
\hline Tuberculosis & $5 / 70$ & $7.15 \%$ \\
\hline Hypertension & $8 / 70$ & 11.42 \\
\hline
\end{tabular}

Table 9 - Patients with different occupation

\begin{tabular}{lcc}
\hline Residential Living & Total & $\%$ \\
\hline Rural & 55 & 78.58 \\
\hdashline Urban & 15 & 21.42 \\
\hline
\end{tabular}

Table 8 - Patients with different life style

\begin{tabular}{lcc}
\hline Life Style & Total & $\%$ \\
\hline Active Workers & 43 & 61.42 \\
\hline Sedentary Workers & 27 & 38.58 \\
\hline
\end{tabular}

\begin{tabular}{|l|l|l|l|l|}
\hline Age (years) & Duo.perfo. & Gast.perfo. & Total (70) & $\%$ \\
\hline $15-25$ & 0 & 6 & 6 & $8.5 \%$ \\
\hline $26-35$ & 2 & 5 & 7 & $10 \%$ \\
\hline $36-45$ & 3 & 9 & 12 & $17.1 \%$ \\
\hline $46-55$ & 4 & 19 & 23 & $32.85 \%$ \\
\hline $56-65$ & 4 & 10 & 14 & $20 \%$ \\
\hline $66-75$ & 1 & 7 & 8 & $11.4 \%$ \\
\hline
\end{tabular}

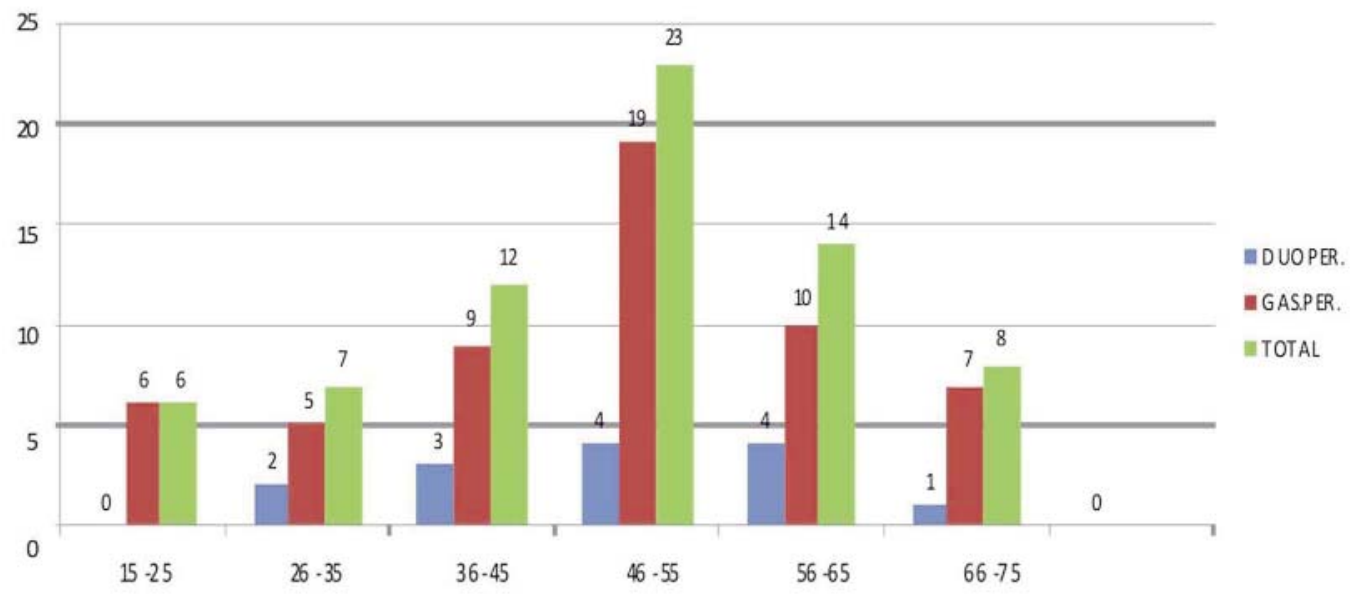

Chart 1 - Age wise distribution 


\begin{tabular}{|l|l|l|l|l|}
\hline Sex & DP (14) & GP (56) & Total (70) & $\%$ \\
\hline Male & 12 & 42 & 54 & $77.14 \%$ \\
\hline Female & 2 & 14 & 16 & $22.85 \%$ \\
\hline
\end{tabular}

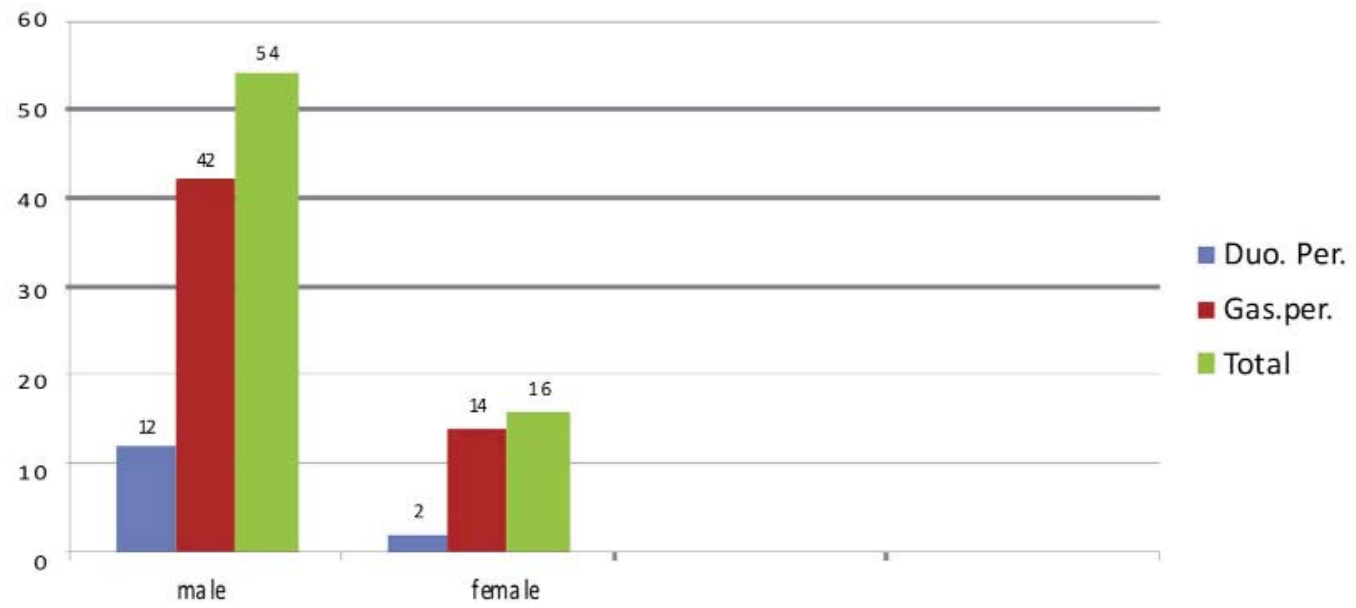

Chart 2 - Sex wise distribution

\begin{tabular}{|l|l|l|}
\hline Number of cases & Total (70) & $\%$ \\
\hline GP & 56 & $80 \%$ \\
\hline DP & 14 & $20 \%$ \\
\hline
\end{tabular}

Gas. Perfo. - Vs - Duo. Perfo.

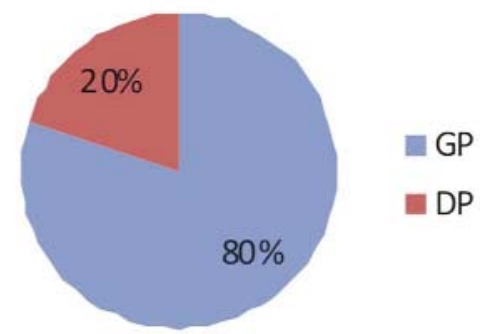

Chart 3 - Patients with duodenal perforation \& gastric perforation

\begin{tabular}{|l|l|l|}
\hline Size of perforation & Total & $\%$ \\
\hline$<1 \mathrm{~cm}$ & 24 & 34.28 \\
\hline $1-2 \mathrm{~cm}$ & 42 & 60 \\
\hline$>2 \mathrm{~m}$ & 4 & 5.72 \\
\hline
\end{tabular}

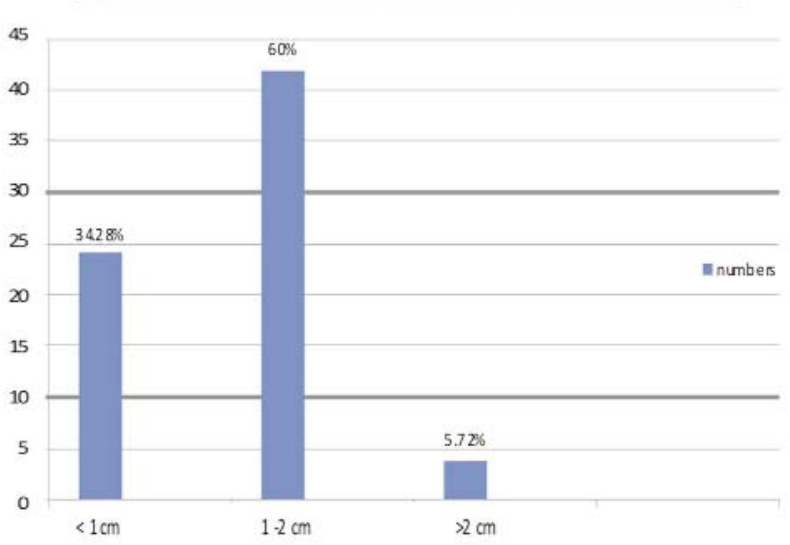

Chart 4 - Patients with different size of perforation

out association and incidence of $\mathrm{H}$. pylori in gastroduodenal perforation.

We found $68.57 \%$ (48 out of 70 cases) patients of peptic perforation were positive for $\mathrm{H}$. pylori. (table 3 )

Out of 70 cases of perforated ulcers the highest 


\begin{tabular}{|l|l|l|}
\hline SITE & TOTAL & $\%$ \\
\hline PREPYLORIC & 38 & 54.28 \\
\hline PYLORIC & 18 & 25.71 \\
\hline DUODENAL & 14 & 20 \\
\hline
\end{tabular}

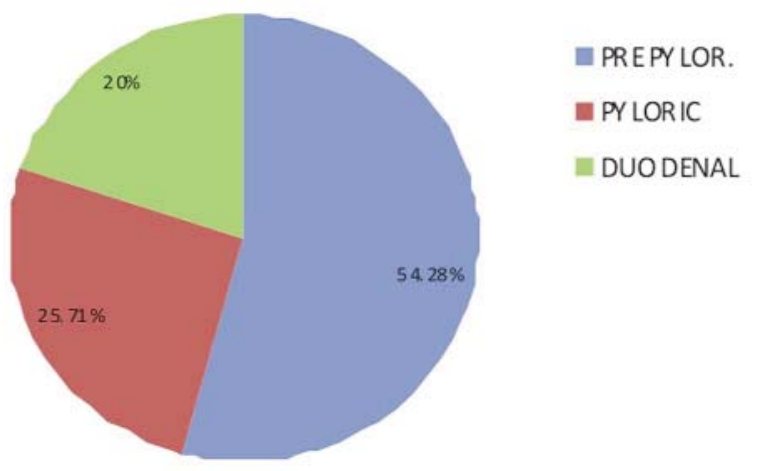

Chart 5 - Patient with the different site of perforation

incidence was between 46 to 55 years (32.85\%). (chart 1) The mean age of presentation was 45.5 years. (table 5) Various case series in India and abroad have mean age of presentation between 40-60 years, and in our study between 46-55 years. I.G Medical College, Shimla, India in 1983-92, showed the mean age of presentations between $41-50$ years, this is nearly consistent with that of our study. A study on perforated peptic ulcer done in JLN Medical College Ajmer Rajasthan India, showed the maximum age incidence between 30-40 years. Kirkpatric et al (1980) reported the mean age of 49 and 51.3 in his two series presented in 1982 and 1986 respectively (12). Hamby et al (1993) reported the mean age of 59 years. This might be due to the different trends of this entity in the Western countries where the elderly patients are the primary victims.

Out of 70 patients, 54 (77\%) were male and 16 (23\%) were female. (chart 2) Male to female ratio was 3:1. Kirkpatric et al (1980) and Boey et al (1982) reported the incidence of males to be $91 \%$ and $85 \%$ respectively. While Hamby et al (1993) reported the incidence of $69 \%$ for males (13). A study in I.G. Medical College Shimla over the period of 10 years from 1983-1992, showed male to female ratio of 17:1.

Use of NSAID is one of the factors generally considered to be important in the development of perforated ulcers. In our study $40 \%$ patients ( 28 out of 70) were taking NSAIDS. (chart 9) Jorgensen et al in a study of 195 patients with acute perforation, found that $18 \%$ had taken NSAID (14). The association between

\begin{tabular}{|l|l|l|}
\hline Results & No. of patients(in 70) & $\%$ \\
\hline H pylori positive & 48 & 68.58 \\
\hline H pylori negative & 22 & 31.42 \\
\hline
\end{tabular}

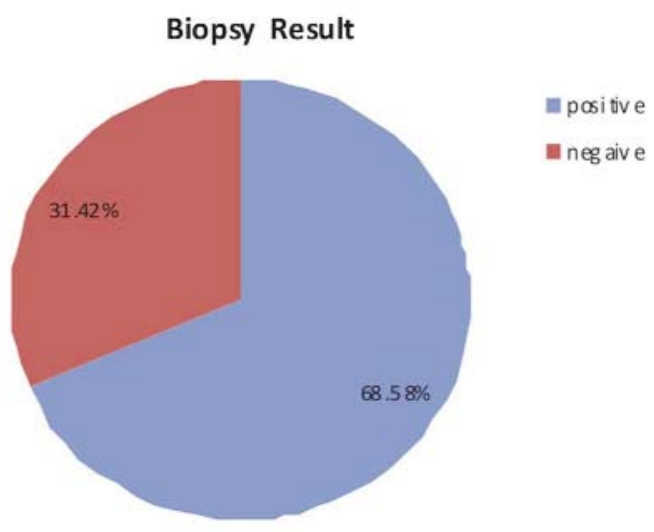

Chart 6 - Results of biopsy test in study (staining of H. pylori by Giemsa and H \& E stain)

\begin{tabular}{|l|l|l|}
\hline PERFORATION & POSITIVE FOR H PYLORI & $\%$ \\
\hline GASTRIC & $40 / 56$ & 71.42 \\
\hline DUODENAL & $8 / 14$ & 57.14 \\
\hline
\end{tabular}

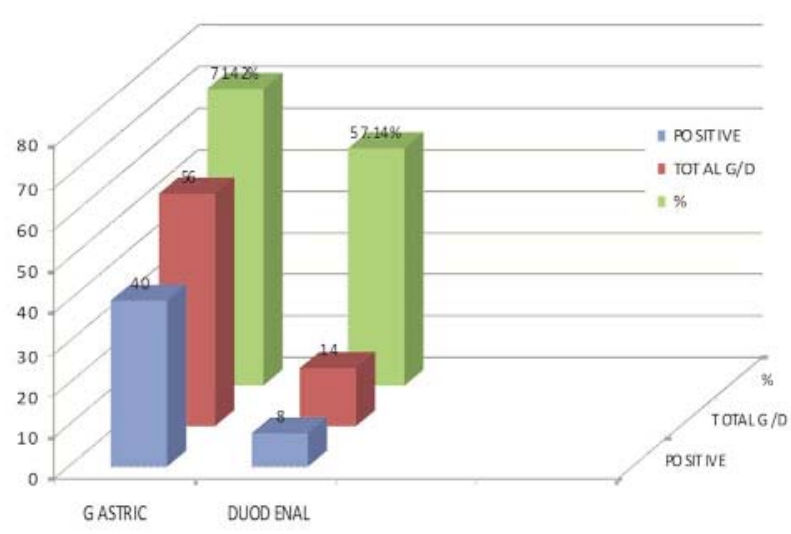

Chart 7 - Positivity of H. pylori in gastroduodenal perforation

aspirin and perforated peptic ulcer was addressed by Duggan in a prospective study of 118 patients with acute perforation.

In our study $31.42 \%$ patients were smokers and were smoking 20 bidi/day and $68.58 \%$ were non-smoker. (chart 10) Although erratic, it seems that disease incidence is increasing among non-smokers. Spencer found that $90.47 \%$ (171 in out of 189) of patients were 
Positivity of biopsy for $\mathrm{H}$ pylori is approximately double in endoscopic antral biopsy as compared to open marginal biopsy (23 patients whom peroperative marginal biopsy was negative having positive biopsy when taken endoscopically)

\begin{tabular}{|l|l|l|}
\hline BIOPSY & $\begin{array}{l}\text { POSITIVE } \\
\text { (IN OUT OF 70) }\end{array}$ & $\%$ \\
\hline $\begin{array}{l}\text { PER-OPERATIVE } \\
\text { (marginal biop sy) }\end{array}$ & $25 / 70$ & 35.7 \\
\hline $\begin{array}{l}\text { POST-O PERATIVE } \\
\text { (endo scopic } \\
\text { antral biop sy) }\end{array}$ & $48 / 70$ & 68.57 \\
\hline
\end{tabular}

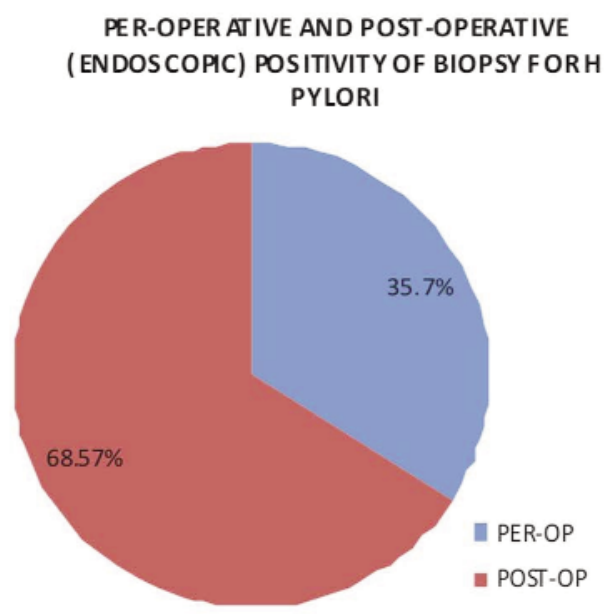

Chart 8 - Positivity of H. pylori in per operative and postoperative biopsy

smokers (15). It has been conclusively shown that smoking delays healing and promotes recurrence of previously healed ulcer (Bailey \& Love).

Out of 70 patients 19 (27.14\%) patients were drinker

\begin{tabular}{|l|l|l|}
\hline H/O NASAIDS & NUMBERS & $\%$ \\
\hline NEGATIVE & 42 & 60 \\
\hline POSITIVE & 28 & 40 \\
\hline
\end{tabular}

History Of NSAIDS Intake

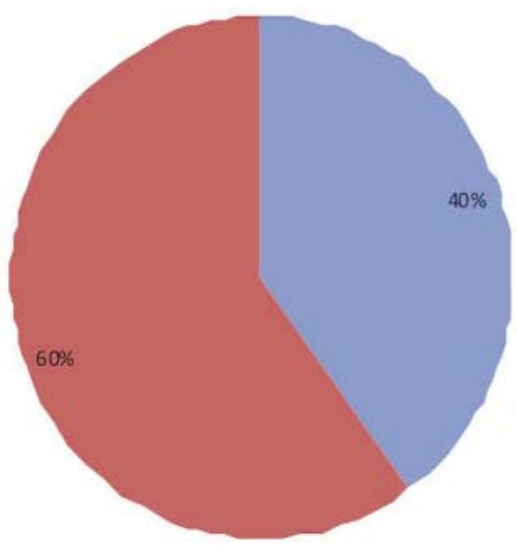

NSAIDS + - NSAIDS .

Chart 9 - Patients with H/O NSAIDS Intake and 51 (72.86\%) patients were non drinker. (chart 11) Although alcohol is always mentioned as a cause of peptic ulcer no study so far shows any definite association between alcohol intake and peptic ulcer disease

\begin{tabular}{|l|l|l|}
\hline H/O SMOKING & NUMBER & $\%$ \\
\hline PRESENT & 22 & 31.42 \\
\hline ABSENT & 48 & 68.57 \\
\hline
\end{tabular}

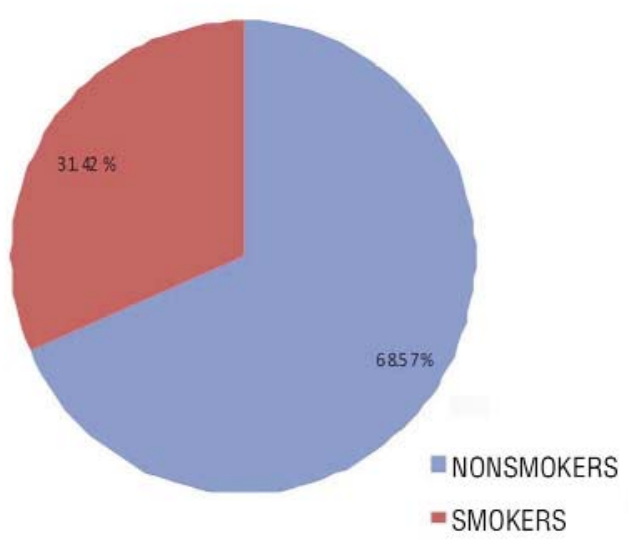

Chart 10 - Patients with cigarette smoking 


\begin{tabular}{|l|l|l|}
\hline H/O ALCOHOL & Total & $\%$ \\
\hline NON ALCOHOLIC & 51 & $72.85 \%$ \\
\hline ALCOHOLIC & 19 & $27.14 \%$ \\
\hline
\end{tabular}

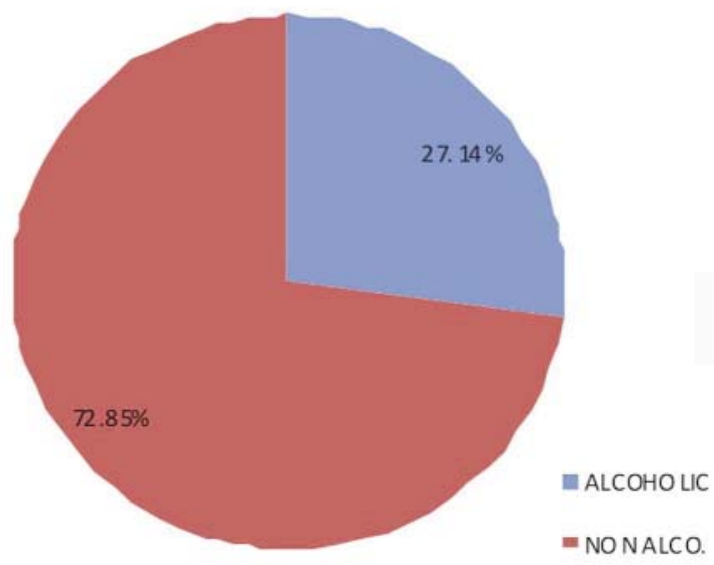

Chart 11 - Patients with alcohol drinking

\begin{tabular}{|l|l|l|}
\hline Economic status & Total & $\%$ \\
\hline High & 4 & $5.71 \%$ \\
\hline Mid dle & 20 & $28.57 \%$ \\
\hline BPL & 46 & $65.71 \%$ \\
\hline
\end{tabular}

$\%$ of patients with different socioeconomic classes

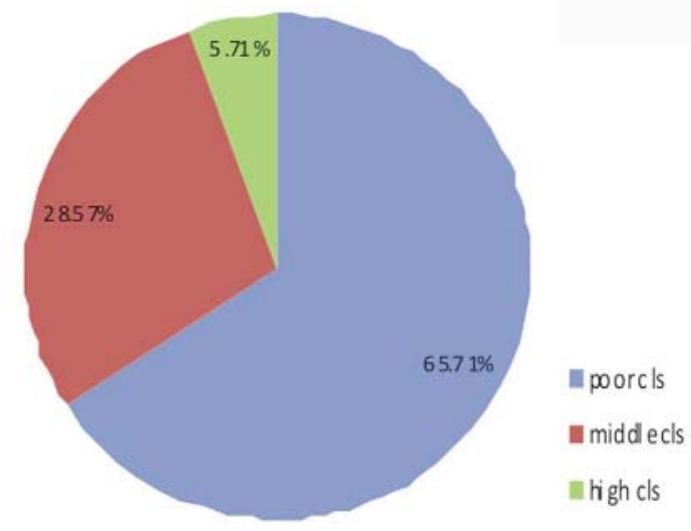

Chart 12 - Patients with different economic status
(Shwartz $8^{\text {th }}$ ed, 958). Walker Hall and Wolf both have reported that third of patients gave history of alcohol consumption (16). In our study there is no increased incidence of peptic ulcer perforation in alcoholic group than non-alcoholic group, so we could not ascribe a cause for this in our study.

Out of 70 patients 46 (65.71\%) patients were belonging to poor economic status and 20 (28.57\%) were belonging to Middle Class and only 4 (5.71\%) patients were belong to high class. (Chart 12) So, in our study it seems that peptic ulcer perforation are more common among poor socioeconomic group patients. This fact is validated from other studies, which have shown similar association. Harrison says that poor socio economic status and low education promote higher colonization rate of $\mathrm{H}$. pylori.

In our study 38 (54.28\%) patients out of 70 patients were vegetarian and $32(45.72 \%)$ out of 70 patients were non vegetarian (table 6), so no conclusive evidence can be drawn from these data. As mentioned in Harrison $16^{\text {th }}$ ed. 1751 , no diet relation has been established with peptic ulceration. In our study 43 (61.42\%) patients were active workers and 27 (38.58\%) out of 70 were sedentary workers. (table 8) So we can conclude that peptic perforation is more common in active workers. Ingrain and Ervin found that 59.9\% (79 of 132 patients) were hard labourers (17).

In our study only 18 patients were educated above $10^{\text {th }}$ class rest 52 patients $(74.28 \%)$ were poorly educated. So from these data it seems that perforated peptic ulcer is more common in poorly educated. In our study 55 (78.58\%) were rural and rest of 15 (21.42\%) were urban residents. (table 9) So, from above data's can be safely said that in Bhopal region the perforation is more common in rural areas with poor economic status and poor education status.

In our study only 4 (5.7\%) patients suffering from tuberculosis, rest were non tubercular. In this study 8 (11.4\%) patients were hypertensive and 62 (88.6\%) patients were normotensive. In study 4 patients were suffering from Ischemic heart disease and 2 from

Table 10 - Complications which were seen in the study

\begin{tabular}{lc}
\hline Complication & Incidence (no of pt /70) \\
\hline Wound infection & 15 \\
\hline Wound dehiscence & 11 \\
\hline Urinary tract infection & 9 \\
\hline Pneumonia & 8 \\
\hline Suture leak & 3 \\
\hline Sepsis & 2 \\
\hline Fistula & 1 \\
\hline Biliary leak & 1 \\
\hline Abscess formation & 0 \\
\hline Bleeding & 0 \\
\hline Stroke & 0 \\
\hline Death & 0 \\
\hline
\end{tabular}




\begin{tabular}{|l|l|l|}
\hline Life Style & Total & $\%$ \\
\hline Active Workers & 43 & 61.42 \\
\hline Sedentary Workers & 27 & 38.58 \\
\hline
\end{tabular}

\section{Active Workers Vs Sedentary Workers}

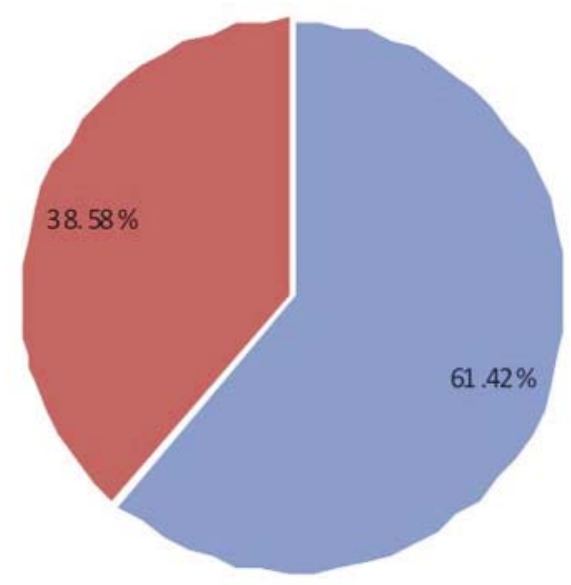

aW

aW

Chart 13 - Patients with different life style

\begin{tabular}{|l|l|l|}
\hline Number of cases & Total (70) & $\%$ \\
\hline GP & 56 & $80 \%$ \\
\hline DP & 14 & $20 \%$ \\
\hline
\end{tabular}

Gas. Perfo. - Vs - Duo. Perfo.

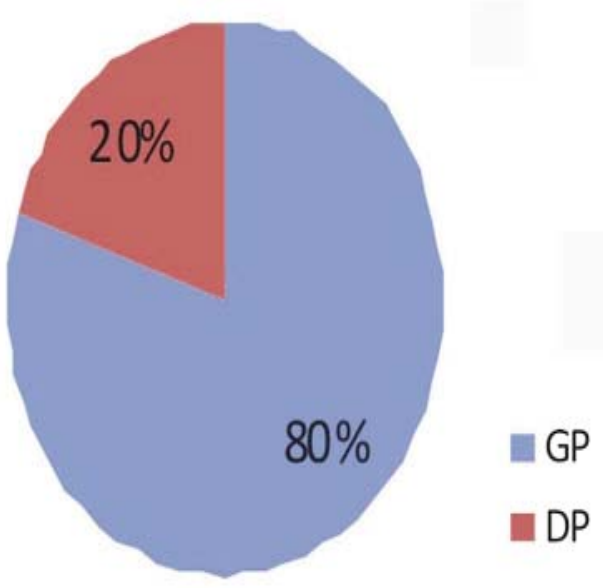

Chart 14 - Patients with duodenal perforation \& gastric perforation
Diabetes mellitus. (table 7) So from above mentioned data's it seems that these disease have nothing to do with perforated peptic ulcer then from general population.

Out of 70 patients, size of perforation in patients is less than $1 \mathrm{~cm} 24(34.28 \%)$ patients, 1 to $2 \mathrm{~cm}$ is 42 $(60 \%)$ and only $4(5.72 \%)$ patients have size of perforation is more than $2 \mathrm{~cm}$. (table 1)

In this study all the cases were having gas under diaphragm in there, X-ray abdomen erect view. In one study conducted in J.L.N Medical College Ajmer 8 of 25 patients plain skiagram abdomen in erect view did not demonstrated free gas under diaphragm.

The demonstration of pneumoperitonium following perforated viscous is however not invariable and most series show that in only $75-80 \%$ of perforation free gas is demonstrated (18).

We found $68.57 \%$ (48 out of 70 cases) patients of peptic perforation were positive for $\mathrm{H}$. pylori. The positivity of $\mathrm{H}$ pylori in Gastric perforation was $71.42 \%$ (40 in out of 56) and in Duodenal perforation the positivity of $\mathrm{H}$ pylori was $57.14 \%$ ( 8 out of 14 ).

Highly variable percentage is reported in literature ranging from $0-92 \%$.

Reinnbach et reported $47 \%$ positivity for $\mathrm{H}$. pylori
(19), Sebastian et al reported $83 \%$ (20), Debongie et al reported $56 \%$ (21), Chowdhary et al reported $0 \%$ (22), Chu et al reported $47 \%$ (23), Sharma et al reported $61 \%$ (24), Metzger et al reported $73 \%$ (25) Kumar et al reported 50\% (26) Papaziogas B, Pavlidis T, et al reported 62.5\% (27) and Ng, Enders K.W.MD, LAM, Y.H. MD et al reported a prevalence of $81 \%$ in perforated peptic ulcer.

Discrepancy between $\mathrm{H}$. pylori infection rate found in different studies may be attributed in part to different population studied.

Enderson et al (2000) also found that simple closure with $\mathrm{H}$. pylori eradication is a useful as any of the definitive surgery in preventing recurrence of ulcer. Donovan et al recommended $\mathrm{H}$. pylori eradication to those who are infected with $\mathrm{H}$. pylori along with simple closure. In our study results are different form the other mentioned studies, quoted above.

So it can be stated that perforated Gastro duodenal ulcer are clearly associated with $\mathrm{H}$. pylori infection as a strong etiological factor and $\mathrm{H}$. pylori infection status should be assessed at the initial endoscopy or operation, regardless of concomitant NSAID intake. If $\mathrm{H}$. pylori infection is found, an appropriate eradication therapy should be initiated as soon as possible as not 
only it is beneficial for eradication of $\mathrm{H}$. pylori but it is also valuable in prevention of ulcer recurrence.

\section{SUMMARY AND CONCLUSION}

1. Most common perforation was Gastric perforation (80\%) and commonest age of perforation was $46-55$ years, men were more affected than females with the ratio of 3:15 Most common size of perforation was between $1-2 \mathrm{~cm}$ in $60 \%$ patients and most common site of perforation was prepyloric region in $38(54.28 \%)$ patients followed by pyloric region then Duodenum.

2. Most of the patient were from poor economic status 46 (65.71\%) and only 4 (5.71\%) patient from high class. Most of the patients were residing in rural area55(78.58\%) and mostly poorly educated (74\%).

3. According to study 28 patients (40\%) were taking NSAIDS, (31.42\%) were smokers, 19 patients (27.14\%) were taking alcohol. So smoking, alcohol, NSAIDS \& steroids all are considered as risk factors for ulcer perforation.

4. In study $38(54.28 \%)$ patients were vegetarian and most of the patients (61.42\%) were active workers. Family history was not significant in any patient.

5. Only $4(5.72 \%)$ patient were tubercular and only 2 (2.86) patients were diabetic. Most of the patients - 62 (88.6\%) were normotensive and 8 (11.4) patients were hypertensive. So these factors are not much related with perforation.

6. On abdomen erect X-Ray film - Gas under the diaphragm was a significant finding.

7. The most common complications were wound infection, wound dehiscence, UTI, and chest complications.

8. The mortality rate and complications increased with increasing age, presence of other comorbid conditions, presence of shock at time of admission and delay in surgery after perforation. The average period of hospitalization was 9 days for perforation patients.

9. Most of the patients -48 ( $68.57 \%$ ) were having $\mathrm{H}$. pylori, detected on biopsy staining by $\mathrm{H} \& \mathrm{E}$ and Giemsa stain. Positivity of $\mathrm{H}$. pylori in gastric perforation was $71.42 \%$ and in duodenal perforation it was $57.14 \%$. So it can be concluded that $\mathrm{H}$. pylori may be the causative factor for gastroduodenal perforation.

10. Study shows that in all factors studied $\mathrm{H}$. pylori was most closely associated factor with perforation.

11. Less than $10 \%$ of patients, who on discharge were prescribed Anti H. pylori kit, had recurrence of ulcer. Thus, $\mathrm{H}$. pylori eradication helps ulcer healing and reduces the incidence of perforation and ulcer recurrence after simple closure of the perforation.

\section{So by the end of this study following conclusion was drawn}

$\mathrm{H}$. pylori is strongly associated with gastroduodenal perforation, (48/70) 68.57\% patients were positive for H. pylori. Gastric perforation was more common than duodenal perforation and prepyloric region was commonest site in this study. Male to female ratio was about 3:1 and most common age group was 46- 55 years. NSAIDS, smoking, alcohol, steroids and stress were the other important risk factors associated with gastroduodenal perforation. For $\mathrm{H}$. pylori detection, biopsy and staining was a good method. Early Anti H. pylori therapy (triple eradication therapy) for patients of gastroduodenal perforation who were positive for $\mathrm{H}$. pylori, provide a exellent cure after simple closure.

In summary our study clearly shows that perforated gastroduodenal ulcer are associated with $\mathrm{H}$. pylori infection as a strong etiological factor and $\mathrm{H}$. pylori infection status should be assessed at the initial endoscopy or operation, regardless of concomitant NSAID intake. If $\mathrm{H}$. pylori infection is found, an appropriate eradication therapy should be initiated as soon as possible, as not only it is beneficial for eradication of $\mathrm{H}$. pylori but it is also valuable in prevention of ulcer recurrence.

\section{REFERENCES}

1. Kurata JH. Ulcer epidemiology: an overview and proposed research framework. Gastroenterology. 1989 Feb;96(2 Pt 2 Suppl):569-80.

2. Penston JG. Review article: clinical aspects of Helicobacter pylori eradication therapy in peptic ulcer disease. Aliment Pharmacol Ther. 1996 Aug;10(4):469-86.

3. Laine L. Approaches to nonsteroidal anti-inflammatory drug use in high risk patient. Gastroenterology. 2001 Feb;120(3):594-606.

4. Blaser MJ. "Who are we? Indigenous microbes and the ecology of human diseases". EMBO Rep. 2006 0ct;7(10):956-60.

5. Stark RM, Gerwig GJ, Pitman RS, Potts LF, Williams NA, Greenman J, et al. Biofilm formation by Helicobacter pylori. Lett Appl Microbiol. 1999 Feb;28(2):121-6.

6. Baldwin DN, Shepherd B, Kraemer P, Hall MK, Sycuro LK, PintoSantini DM, et al. Identification of Helicobacter pylori genes that contribute to stomach colonization. Infect Immun. 2007 Feb;75(2): 1005-16. Epub 2006 Nov 13.

7. Brown LM. Helicobacter pylori: epidemiology and routes of transmission. Epidemiol Rev. 2000;22(2):283-97. 
8. Mittal S, Trakroo S, Kate V, Jagdish S. Evaluation of the effect of presence of blood in the stomach on endoscopic diagnostic tests forHelicobacter pylori infection. Indian J Med Microbiol. 2011 OctDec;29(4):379-82. doi: 10.4103/0255-0857.90170.

9. Suganuma M, Yamaguchi K, Ono Y, Matsumoto H, Hayashi T, Ogawa T, et al. TNF-alpha-inducing protein, a carcinogenic factor secreted from H. pylori, enters gastric cancer cells. Int J Cancer. 2008 Jul 1; 123(1):117-22. doi: 10.1002/ijc.23484.

10. Pounder RE, $\mathrm{Ng} \mathrm{D}$. The prevalence of Helicobacter pylori infection in different countries. Aliment Pharmacol Ther. 1995;9 Suppl 2:339.

11. Stenström B, Mendis A, Marshall B. Helicobacter pylori--the latest in diagnosis and treatment. Aust Fam Physician. 2008 Aug;37(8):60812.

12. el-Omar EM1, Penman ID, Ardill JE, Chittajallu RS, Howie C, McColl KE. Helicobacter pylori infection and abnormalities of acid secretion in patients with duodenal ulcer disease. Gastroenterology. 1995 Sep;109(3):681-91.

13. Hermansson M, Staël von Holstein C, Zilling T. Surgical approach and prognostic factors after peptic ulcer perforation. European Journal of Surgery. 1999;165(6):566-72.

14. Andersen IB, Jørgensen T, Bonnevie 0 , Grønbaek M, Sørensen TI.Smoking and alcohol intake as risk factors for bleeding and perforated peptic ulcers: a population-based cohort study. Epidemiology. 2000 Jul;11(4):434-9.

15. Strang $\mathrm{C}$, Spencer I0. Factors associated with perforation in peptic ulcer. Spencer. Br Med J. 1950 Apr 15;1(4658):873-6.

16. Shipley ER, Walker JH. Perforated gastric and duodenal ulcers; an analysis of 200 consecutive cases. Am J Surg. 1949 Mar;77(3):32937.

17. Ingram IN, Ervin JR. Acute perforated gastroduodenal ulcer. Am J Surg. 1952 Jul;84(1):30-41.
18. Hermansson M, Staël von Holstein C, Zilling T. Peptic ulcer perforation before and after the introduction of H2-receptor blockers and proton pump inhibitors. Scand J Gastroenterol. 1997 Jun;32(6):523-9.

19. Reinbach DH, Cruickshank G. McColl KE. Acute perforated duodenal ulcer is not associated with Helicobacter pylori infection. Gut. 1993 Oct;34(10):1344-7.

20. Suerbaum S, Michetti P. Helicobacter pylori infection. N Engl J Med. 2002 Oct 10;347(15):1175-86.

21. Forbes GM, Collins BJ, McCullough CA, Coombs GW, Robins PD. Short duration therapy for Helicobacter pylori in Western Australia: the impact of metronidazole resistance. Aust N Z J Med. 1998 Feb;28(1): 13-7.

22. Chowdhary SK, Bhasin DK, Panigrahi D, Malik AK, Kataria RN, Behra A, et al. Helicobacter pylori infection in patients with perforated duodenal ulcer. Trop Gastroenterol. 1998 Jan-Mar;19(1):19-21.

23. Lanas A1, Fuentes J, Benito R, Serrano P, Bajador E, Sáinz R. Helicobacter pylori increases the risk of upper gastrointestinal bleeding in patients taking low-dose aspirin. Aliment Pharmacol Ther. 2002 Apr:16(4):779-86.

24. Laine L, Fennerty MB, Osato M, Sugg J, Suchower L, Probst P, et al. Esomeprazole-based Helicobacter pylori eradication therapy and the effect of antibiotic resistance: results of three US multicenter, doubleblind trials. Am J Gastroenterol. 2000 Dec;95(12):3393-8.

25. Metzger J, Styger S, Sieber C, von Flüe M, Vogelbach P, Harder F. Prevalence of Helicobacter pylori infection in peptic ulcer perforations. Swiss Med Wkly. 2001 Feb 24;131(7-8):99-103.

26. Talley NJ, Vakil N, Ballard ED 2nd, Fennerty MB. Absence of benefit of eradicating Helicobacter pylori in patients with nonulcer dyspepsia. N Engl J Med. 1999 Oct 7;341(15):1106-11.

27. Papaziogas B, Pavlidis T, Papaziogas T. Helicobacter pylori infection and complicated peptic ulcer. Swiss Med Wkly. 2001 Jul 28;131(2930):442. 